\title{
Marketing Small Towns: A Preliminary Investigation
}

Katherine A. Fraccastoro, Lamar University, USA

Komal Karani, Lamar University, USA

\begin{abstract}
This study is a preliminary investigation into the marketing processes used by small towns/cities to attract business revenue and tourism dollars. Because small town governments do not have the resources of large cities to spend on marketing, it is unclear if they utilize the marketing process in a manner similar to large cities or businesses. Personal interviews were used to determine the process by which small towns attract businesses to their area as well as develop tourism. Small towns must develop business opportunities to encourage economic development in their cities as well as create tourism opportunities to increase the economic impact in the area. The findings indicate that, while some similarities exist due to common goals, different processes are used by different size cities. While the process for economic development through the attraction of businesses is similar in most cities, the process to create tourism differs for small towns. The smaller towns do not utilize the full marketing process which could create a better brand identity that could make them more successful. Instead, they take a more entrepreneurial approach by sharing resources and developing partnerships with other small towns to utilize their resources more effectively.
\end{abstract}

Keywords: Marketing Small Towns; Tourism Marketing; Business Marketing; Place Marketing

\section{INTRODUCTION}

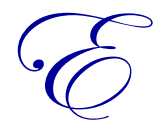

conomic development is an important part of any strategic growth plan for a city. More and more cities are competing for business investments and tourism dollars by trying to attract new companies and increase tourism and visitor opportunities. As such, determining the best ways to develop and/or enhance the local economy and market the city is a major consideration by city planners. Large cities have the tax base and funding necessary to hire marketing professionals to assist in the creation of a city identity and marketing of their areas for growth. Small cities, towns, and communities have substantially fewer funds with which to meet all the needs of their areas while also trying to attract business and tourism dollars. It is more likely that small cities, towns, and communities will take a more entrepreneurial approach to marketing where they utilize their limited resources by having key officials take on multiple roles, including marketing of the area.

\section{LITERATURE REVIEW}

The marketing and branding of places in order to increase tourism and/or encourage economic development have been studied in various contexts. According to Louro and Cunha (2001), branding a locale highlights its meaning in terms of its benefits, style, and culture to outsiders. In place marketing literature, many articles discuss how marketing should be conducted to attract tourism; however, often those guidelines are not utilized in an appropriate manner, if at all (Kavaratzis \& Ashworth, 2005; Jamrozy \& Walsh, 2008). Some studies look at different major cities and how they have engaged in marketing programs to brand or rebrand themselves (Bramwell \& Rawding, 1996; Miller, 1997; West, 1997).

Other studies assess factors that may be influential in encouraging tourism in major cities. Researchers have suggested that domestic travel and local participation (Bennet \& Savani, 2003; Mbaiwa, Toteng, \& Moswete, 2007), pull factors such as socio-cultural facilities and services that can attract large tourist numbers (Leiper, 1979; 
Law, 2002; Bennet \& Savani, 2003; Mbaiwa et al., 2007), ties between tourist attractions and host communities (Leiper, 1979; West, 1997; Law, 2002; Mbaiwa et al., 2007), population numbers (Mbaiwa et al., 2007), government policies (Bennet \& Savani, 2003), integration between tourism and government planning (West, 1997; Mbaiwa et al., 2007), urban regeneration (Bennet \& Savani, 2003), utilization of brand marketing techniques (West, 1997; Bennet \& Savani, 2003), and area prices (Mbaiwa et al., 2007) are all factors that can affect successful urban tourism.

While there are a number of studies that examine urban tourism (see Mbaiwa et al., 2007, for a historical perspective of the topic) and some that focus on specific attempts by cities to increase tourism and/or rebrand cities (Rantisi \& Leslie, 2006; Gotham, 2007; Patterson, 2010), studies are lacking that examine the actual process used by cities to develop businesses and tourism as an integrated part of their economic development process, with Bennet and Savani (2003) being the exception. In the previously-mentioned studies, all of the cities have been large, metropolitan areas or major cities within the country in which the study took place (Bennet \& Savani, 2003 London, Copenhagen, and Boston, Massachusetts; Rantisi \& Leslie, 2006 - Montreal, Gotham; 2007 - New Orleans, Louisiana; Mbaiwa et al., 2007 - Gaborone and Maun, Botswana; Patterson, 2010 - Liverpool).

Smaller cities, towns, and communities are undertaking revitalization and economic development efforts similar to large cities and trying to market themselves with far fewer resources. Of the 19,540 incorporated areas in the United States, only 273 have a population of more than 100,000 (US Census Bureau, 2012). Since the majority of incorporated areas are considerably smaller than 100,000 people (18,835 areas with 0-49,999 and 432 areas with 50,000 - 99,999 from the US Census Bureau, 2012), there is a need to explore the process used by these small towns to determine how, if at all, marketing is being used to develop business and tourism opportunities. Marketing should be an important part of this process to develop the relationships necessary to develop the economy, as well as generate awareness of the economic development projects and publicize all related events.

\section{STUDY}

This study is a preliminary investigation into the process that is used by smaller cities to market themselves. The collaborative destination marketing framework by Wang and Xiang (2007) suggests that in order to evaluate tourism organizations' behavior in forming marketing alliances and networks, four main areas should be examined: (1) preconditions for marketing alliances, which include the economic, social, and environmental conditions for the alliance and network formation; (2) motivations of the parties involved in the process; (3) an understanding of the process of how the relationships develop and are maintained; and (4) an assessment of the outcomes of the alliances and networks and an evaluation of the continuation of the relationship. These factors will be considered during this evaluation. In addition, assessments will be made as to the extent of marketing and branding used by small towns, the process used to determine which business and tourism opportunities are best to pursue, if any, and the procedures used to bring in new businesses, special events, and the like in efforts to increase the economic impact on the area.

\section{DATA COLLECTION PROCEDURE}

The study uses face-to-face and telephone interviews with chief executive officers and marketing directors of economic development corporations (EDC) and directors of convention and visitors bureaus (CVB) to determine how smaller towns are developing new businesses and bringing in events to increase tourism in their area. The interview procedure follows that recommended by Eisenhardt (1989), which indicates that the literature should be used to formulate the research question and potentially important variables, but the researcher should keep an open mind about the relationships among variables. When conducting interviews, the researcher should be flexible, utilizing general questions developed from the literature which still allows the respondent to add vital information and anecdotes that may provide additional insight.

Thirteen questions were developed based on the literature during the interviews. The questions, along with interview responses, are listed in Table 1. These questions allow the respondents to provide detailed information relevant to their particular contributions and/or thoughts as to the marketing and/or economic development of the area. The intent is to determine information that can be used to develop a questionnaire to further study the process 
used by small towns to market themselves. Several small towns in the southeastern United States were used for this preliminary investigation.

\section{FINDINGS}

The findings indicate that every town considered utilizes an EDC and CVB of some type. Larger cities can support their own EDCs and CVBs while smaller towns tend to share resources. The EDCs are all structured in a similar manner outside the construct of the city government. The CVBs have three types of structures - independent (outside city government), part of the Chamber of Commerce, or part of the city government. This structure is related to size. The smaller towns are most likely to have CVBs as part of the city government, whereas larger cities tend to have an independent structure. The cities in between utilize their CVBs as part of the Chamber of Commerce (Table 2).

All EDCs utilize very similar processes when attempting to attract businesses to their communities. There is a formal process in which the cities utilize computer software to match the specifications of their cities with the needs of businesses to determine the likelihood of a retailer to locate in an area. Once retailers with whom the city has a match are found, the city then pursues the retailer to attempt to entice them to locate in the area. They utilize various tools to try to promote their cities, including site selectors, retail conferences, state conferences, websites, business recruiters, key consultants, and social media. The EDCs do engage in strategic planning with the city to determine the image and identity they wish to promote. The do have impact on the infrastructure of the city, meaning they can make suggestions for improvement as well as fund some of the changes necessary to attract business to the area. EDCs are mainly targeting businesses in the area, as well as attracting new business with their efforts. They are not focused on communicating with residents or tourists. They do utilize some tracking measures to determine their success in attracting business, such as sales tax allocation spikes, hotel occupancy, and new business growth.

Table 1: Interview Questions

Q1: What has the city done to develop and/or better its image/build an identity?

Q2: How does it bring in commerce?

Q3: How does the city communicate the information? To whom?

Q4: Does everyone get the same message? Different messages to different people?

Q5: Do you use external marketing consultants?

Q6: Do you have to address internal structural issues to bring in commerce? (such as infrastructure, economics, disadvantaged residence, poor housing, social deprivation, high crime, environmental pollution, industrial dereliction, poor image)

Q7: Where do you get ideas? (roundtable, other cities, etc.)

Q8: Who decided it was necessary to rebrand/market the city?

Q9: Which people are most influential in determining the direction of the changes?

Q10: How do you determine if you are successful? What types of measures to you use?

Q11: What types of investments are required/needed? (promotion/public relations, image building, influencing politicians, convincing local funders, etc.)

Q12: Take us through your decision process/marketing process.

Q13: What do you feel are your three biggest challenges?

\begin{tabular}{l}
\multicolumn{2}{l}{ Table 2: EDC and CVB Structure by City Size } \\
\begin{tabular}{|l|l|l|}
\hline \multicolumn{1}{|c|}{ City Size } & \multicolumn{1}{|c|}{ EDC } & \multicolumn{1}{c|}{ CVB } \\
\hline 53,818 & For city & Independent \\
\hline 18,595 & For city, also for county & Part of local Chamber of Commerce and part of county Chamber of Commerce \\
\hline 17,547 & For city & Part of local Chamber of Commerce \\
\hline 14,393 & Share with sister city & Part of local Chamber of Commerce \\
\hline 13,040 & Share with sister city & Part of local Chamber of Commerce \\
\hline 7,840 & For county & Part of local Chamber of Commerce and Part of County Chamber of Commerce \\
\hline 2,097 & For county & Part of City and part of County Chamber of Commerce \\
\hline
\end{tabular}
\end{tabular}

CVBs are very different in their approach to marketing the city for tourism. They appear to follow a marketing approach, although they must work with what the city has to offer. They cannot develop offerings for a 
particular target; thus, they assess their towns and determine who would most likely benefit from what is in the area, and then they pursue those consumers. If they can afford to do so, the CVBs utilize outside consultants to conduct surveys to help determine the most appropriate ways to brand the cities as well as develop tag lines to be used in any promotional efforts. The CVBs target specific groups of consumers with their marketing efforts. There are three main classifications of target consumers - leisure travel, group travel, and conventions. Most CVBs participate in cooperative efforts with other cities in the area (large and small) to stretch their advertising dollars. They utilize numerous tools to promote their offerings, including trade shows, billboards, printed materials, advertising (especially magazine), and social media. They do not have a direct impact on the infrastructure of the city, although they can suggest beautification along certain routes that are likely to be taken by tourists. They do try to measure their marketing impact through number of inquiries, conversions from inquiries to tourism (through surveys), labels (magazine inserts), banner ad "click-throughs" (the number of times a consumer clicks on the banner ad), and surges in inquiries during advertising periods.

\section{CONCLUSION}

This preliminary investigation into the marketing of small towns has determined that there are two separate marketing processes being used to help small towns grow. One process is used by the EDCs to develop business growth in the area and the other process is used by the CVBs to develop tourism in the area. Each process is unique and does follow the marketing process in some ways. The study does find that the smaller the city, the more entrepreneurial in becomes in the marketing process, meaning smaller towns must utilize more cost efficient methods to marketing themselves by participating in as many cooperative efforts as possible to stretch the limited resources that are available to them.

\section{FUTURE RESEARCH}

From this study, a set of factors will be developed that can be used as indicators of the factors involved in the process of marketing small towns. A new study will survey additional small towns to determine the validity of these factors and attempt to tie the factors to the economic success of the city to determine the predominant indicators that influence the successful marketing of a small town. The purpose is to assess how market planning, target marketing, and development of a marketing mix can be adapted for the specific needs of small cities, towns, and communities that lack resources and, often, professional expertise to utilize the marketing process to its fullest extent.

\section{AUTHOR INFORMATION}

Katherine Fraccastoro is an Associate Professor of Marketing at Lamar University, Beaumont, Texas. She holds a $\mathrm{Ph}$.D. from Louisiana State University and her research interests include consumer behavior issues related to product pricing, cultural acceptance issues, entrepreneurship, and marketing education. She has published several referred papers on these and related issues in conference proceedings and journals such as the Journal of Consumer Behavior, Marketing Letters, Journal of Higher Education Policy and Management, and Communications of the Association for Information Systems. Currently Dr. Fraccastoro is the Ronald Rodriguez Faculty Scholar in Business. E-mail: Kathy.fraccastoro@lamar.edu (Corresponding author)

Komal Karani is an Assistant Professor of Marketing and Entrepreneurship at Lamar University, a member of the Texas State University System. She holds a PhD from Drexel University of Philadelphia and her research interests center on social media marketing, aging consumers, services marketing, and satisfaction. Her work has appeared in such journals as the Journal of Management and Marketing Research, Journal of International Academy for Case Studies, Economic Affairs, and Journal of Business and Economics Research. E-mail: komal.karani@lamar.edu

\section{REFERENCES}

1. Bennet, R., \& Savani, S. (2003). The rebranding of city places: An international comparative investigation. International Public Management Review, 4(2), 70-87. 
2. Bramwell, B., \& Rawding, L. (1996). Tourism marketing image of industrial cities. Journal of Tourism Research, 23(1), 201-221.

3. Eisenhardt, K. M. (1989). Building theories from case study research. Academy of Management Review, 14(3), 532-550.

4. Gotham, K. F. (2007). (Re)branding the big easy: Tourism rebuilding in post-Katrina New Orleans. Urban Affairs Review, 42(6), 823-850.

5. Jamrozy, U., \& Walsh, J. A. (2008). Destination and place branding: A lost sense of place? In S. F. McCool $\&$ R. N. Moisey (eds.), Tourism, recreation and sustainability linking culture and the environment $\left(2^{\text {nd }}\right.$ ed., pp. 131-141). Cambridge, MA: CABI International.

6. Kavaratzis, M., \& Ashworth, G. J. (2005). City branding: An Effective assertion of identity or a transitory marketing trick? Tijdschrift voor Economische en Sociale Geografie, 96(5), 506-514.

7. Law, C. M. (2002). Urban tourism: The visitor economy and the growth of large cities. London: Continuum.

8. Leiper, N. (1979). The framework of tourism: Towards a definition of tourism, tourist, and the tourism industry. Annals of Tourism Research, 6(4), 390-407.

9. Louro, M. J., \& Cunha, P. V. (2001). Brand management paradigms. Journal of Marketing Management, $17(7 / 8), 849-875$.

10. Mbaiwa, J. E., Toteng, E. N., \& Moswete, N. (2007). Problems and prospects for the development of urban tourism in Gaborone and Maun, Botswana. Development Africa, 24(5), 725-739.

11. Miller, R. (1997). Sales from the city. Marketing, 11(September), 31-34.

12. Patterson, A. (2010). Extreme cultural and marketing makeover: Liverpool home edition. In: O’Reilly, Daragh, \& Kerrigan, Marketing the arts: A fresh approach, Finola, ed., London, Routledge.

13. Rantisi, N. M., \& Leslie, D. (2006). Branding the design metropole: The case of Motreal, Canada. Area, 38(4), 364-376.

14. US Census Bureau (2012). Incorporated places by population size. Retrieved from http://www.census.gov/ compendia/statab/2012/tables/ 12s0028.pdf

15. Wang, Y., \& Xiang, Z. (2007). Toward a theoretical framework of collaborative destination marketing. Journal of Travel Research, 46(1), 75-85.

16. West, R. (1997). Slicker cities. Marketing Business, May, 10-14. 


\section{NOTES}

